\title{
Metasternal Gland Volatiles and Sexual Communication in the Triatomine Bug, Rhodnius prolixus
}

\author{
Gina B. Pontes • Björn Bohman • C. Rikard Unelius • \\ Marcelo G. Lorenzo
}

Received: 15 June 2007 /Revised: 26 November 2007 / Accepted: 9 January 2008 / Published online: 4 March 2008

(C) Springer Science + Business Media, LLC 2008

\begin{abstract}
Twelve compounds produced by the metasternal glands (MGs) of the triatomine bug Rhodnius prolixus were identified by solid phase microextraction (SPME) combined with coupled gas chromatography-mass spectrometry (GC-MS) using achiral and chiral columns. All substances were ketones or alcohols, and the same compound profile was found in the secretions produced by either sex. The most abundant compounds were 2-methyl-3-buten-2-ol, (2S)-pentanol, (3E)-2-methyl-3-penten-2-ol, and (2R/2S)-4methyl-3-penten-2-ol. Emission of these compounds was detected more frequently from females than males, and females released them more frequently during the early hours of the scotophase, the period when sexual activity in this species is at its peak. These compounds were also detected in the headspace above mating pairs. Finally, the occlusion of the MG orifices of male or female bugs with paraffin resulted in a significant decrease in copulation frequency compared to sham-operated insects. Together, these data suggest that the MG secretions of $R$. prolixus may be involved in sexual communication.
\end{abstract}

Keywords Rhodnius prolixus · Sexual behavior . Metasternal glands $\cdot$ Pheromone $\cdot$ Volatiles · Identification

G. B. Pontes $\cdot$ M. G. Lorenzo $(\bowtie)$

Laboratory of Triatomines and Chagas Disease Epidemiology, Instituto René Rachou/FIOCRUZ,

30190002 Belo Horizonte, Minas Gerais, Brazil

e-mail: marcelo@cpqrr.fiocruz.br

B. Bohman · C. R. Unelius

School of Pure and Applied Natural Sciences,

University of Kalmar,

SE-391 82 Kalmar, Sweden

\section{Introduction}

Rhodnius prolixus Stål 1859 (Heteroptera: Reduviidae) is the main vector of Chagas disease in northern South America and in parts of Central America (Schofield 1994). This species is well adapted to live in rural houses and is considered to be of major epidemiological importance (Monteiro et al. 2003). Approximately 16-18 million people in Latin America are infected with the Chagas disease parasite, Trypanosoma cruzi, and another 120 million are at risk (WHO 2005).

Baldwin et al. (1971) reported that copulating pairs of $R$. prolixus emit a pheromone that is attractive to males. This phenomenon has also been observed for another vector of Chagas disease, the bug Triatoma infestans (Manrique and Lazzari 1995). Relatively little is known about the mechanisms of long- or short-distance orientation that mediate sexual encounters between adults of species in the subfamily Triatominae, although Baldwin et al. (1971) suggested that feeding triggers the development of sexual attraction in $R$. prolixus and that unfed males of this species do not respond to the apparent odor emitted by mating pairs.

$R$. prolixus adults have a pair of metasternal glands (MGs) that open to the ventral metathorax (Brindley 1930). Their function and the chemical identity of any secretions are unknown. Another set of glands of this insect, the Brindley's glands, which secrete isobutyric acid as the most abundant compound, are likely associated with alarm and defense functions (Ward 1981; Cruz López et al. 1995; Rojas et al. 2002; Manrique et al. 2006). It has been suggested that compounds produced by Brindley's glands are involved in the sexual chemical communication of triatomines (Cruz López et al. 2001; Rojas et al. 2002; Guerenstein and Guerin 2004). 
In a recent study, Manrique et al. (2006) suggested that the secretions of the MGs of T. infestans are involved both in sexual and alarm communication, and that the secretions of Brindley's glands are restricted to alarm and defensive roles. These authors identified several highly volatile ketones and alcohols produced by the MGs and showed that the contents of these glands are emitted by adults of this species during copulation.

Our primary objective in this study was to identify volatile secretions produced by the MGs of $R$. prolixus. We further tested whether the MG compounds are emitted at different phases of the light/dark cycle by virgin males and females and examined if mating pairs of this species emit these substances. Finally, we tested whether the compounds emitted from these glands influence copulation.

\section{Methods and Materials}

Insects Insects were reared at $26 \pm 2^{\circ} \mathrm{C}$ and $60 \pm 10 \%$ r.h. Groups of fifth instars were sorted by sex and placed in separate flasks to keep them unmated until use in experiments. All insects used were kept under the 12:12 L:D photoperiod for at least $3 \mathrm{~d}$ before any experiment. Virgin insects were used for all experiments, and their nutritional status was varied according to the experiment performed. For odor-identification studies, unfed insects were dissected at d 20 after ecdysis. For the detection of emission of $\mathrm{MG}$ compounds, insects were fed at d 10, and used $20 \mathrm{~d}$ after ecdysis. For the remaining two experiments (i.e., detection of emission of MG odors during mating and evaluation of the effect of gland occlusion on mating success), insects were used at d 20 after being fed at d 10. All assays were performed at $26 \pm 2{ }^{\circ} \mathrm{C}$ and $60 \pm 10 \%$ r.h.

\section{Identification of Compounds Produced by Metasternal} Glands Samples of 12 glands were obtained from six insects and stored in 2-ml vials sealed with Teflon ${ }^{\circledR /}$ silicone-lined caps. Control samples were prepared with pieces of tissue and cuticle from hind leg coxae. Female and male tissue was stored at $-8^{\circ} \mathrm{C}$ for not more than $10 \mathrm{~d}$ before analysis. No change of the chemical profile was observed after storage when compared with freshly prepared samples.

Gland samples were sonicated (Thornton T14, Inpec Eletrônica, Brazil, $40 \mathrm{kHz}$ ) for $5 \mathrm{~min}$ and then heated at $50^{\circ} \mathrm{C}$ for $30 \mathrm{~min}$. A solid phase microextraction (SPME) fiber (2 cm, DVB/CAR/PDMS-50/30 $\mu \mathrm{m}$, Supelco, Bellefonte, PA, USA) was exposed in the headspace of the samples (in vials) for $10 \mathrm{~min}$ at $50^{\circ} \mathrm{C}$ immediately before analysis by gas chromatography-mass spectrometry (GC-MS). GC-MS analysis was performed by using coupled Shimadzu 17A-5050A machines. Desorption time in the splitless injection port of the GC was $1 \mathrm{~min}$. Helium at $30 \mathrm{~cm} \mathrm{~s}^{-1}$ was used as carrier gas. Transfer line and GC injector temperatures were 250 and $230^{\circ} \mathrm{C}$, respectively. Analyses were performed by using a SupelcoWax-10 column $(30 \mathrm{~m} \times 0.25 \mathrm{~mm}$ i.d. $\times 0.25 \mu \mathrm{m}$ film; Supelco), with an oven program of $40^{\circ} \mathrm{C}$ for $5 \mathrm{~min}$, $3^{\circ} \mathrm{C} \min ^{-1}$ to $120^{\circ} \mathrm{C}$, then $15^{\circ} \mathrm{C} \mathrm{min}^{-1}$ to $200^{\circ} \mathrm{C}$.

Tentative identification of volatile compounds was based on the comparison of retention indices (Kováts 1965) and mass spectra with data from the literature and spectral library (NIST-02). All tentative identifications were confirmed by peak enhancement in co-injections with authentic synthetic samples (Birkett et al. 2004). A typical procedure for co-injection/peak enhancement is given for 2-pentanol: A gland sample was prepared and analyzed as described. After a chromatogram was obtained, the gland sample was treated again according to the same protocol (i.e., sonicated, heated, and sampled by SPME). In parallel, a sample of synthetic standard was prepared: $1 \mu \mathrm{l}$ of the compound was absorbed on a small piece of filter paper $(1 \times 1 \mathrm{~cm})$ in a $10-\mathrm{ml}$ open vial. The vial was heated at $50^{\circ} \mathrm{C}$ for $3 \mathrm{~min}$ and cooled to ambient temperature for $1 \mathrm{~min}$. The same SPME fiber was exposed to the standard sample for $2 \mathrm{sec}$, and the odors were desorbed from the fiber into the GC injector. The results of both injections were compared and the identity of the compound confirmed when three criteria were fulfilled. First, the peak from the MG compound and the synthetic compound overlapped fully. Second, the peak area increased in the second injection. Third, no difference between the mass spectral profiles was observed after a scan-by-scan analysis.

The stereochemistry of chiral compounds was determined by GC with flame-ionization detection (FID; Shimadzu 17A) and GC-MS analysis. Gland samples were heated at $50^{\circ} \mathrm{C}$ for $30 \mathrm{~min}$, and the SPME fiber was exposed in the headspace for a given time depending on the relative abundance of a compound. The method used for analysis was the same as for the GC-MS analysis, except the carrier gas velocity was $31 \mathrm{~cm} \mathrm{sec}^{-1}$, the injector and detector temperatures were both $225^{\circ} \mathrm{C}$, and a CYCLOSILB column $(30 \mathrm{~m} \times 0.25 \mathrm{~mm}$ i.d. $\times 0.25 \mu \mathrm{m}$ film, J \& W Scientific) at either $80^{\circ} \mathrm{C}$, for 4-methyl-3-penten-2-ol, or $30^{\circ} \mathrm{C}$, for the other compounds, was used. Because a number of peaks overlapped with this column and conditions, chiral GC-MS analysis was carried out by using a GammaDex 225 column $(30 \mathrm{~m} \times 0.25 \mathrm{~mm}$ i.d. $\times 0.25 \mu \mathrm{m}$ film) at $30^{\circ} \mathrm{C}$. The retention times of compounds were compared with synthetic standards, and co-injection (peak enhancement) was carried out to confirm the identities of the enantiomers of all compounds. The configuration of 2 methyl-3-penten-2-ol was confirmed by co-injection with the synthetic $(E)$-isomer, derived from trans-methyl crotonate (for synthesis details, see below). 
Emission of MG Compounds by Virgin Adults Groups of three virgin adults of the same sex were separated $7 \mathrm{~d}$ after ecdysis and transferred into $10-\mathrm{ml}$ vials covered with gauze with a piece of filter paper inside as a substrate for the bugs. These vials were enclosed separately in 150-ml closed plastic containers so as to isolate each group of bugs. We worked with groups of insects to increase both the likelihood of emission and the amount of MG odors (preliminary assays with individual insects failed probably because of low levels of compounds). Each treatment included three groups of three insects. The different series of assays monitored odor emission by: (1) unfed females during the dark phase; (2) unfed females during the light phase; (3) females fed at d 9 after ecdysis, during the dark phase; (4) females fed at d 9 after ecdysis, during the light phase; (5) unfed males during the dark phase; (6) unfed males during the light phase; (7) males fed at $d 9$ after ecdysis, during the dark phase; and (8) males fed at d 9 after ecdysis, during the light phase. Odor sampling with a SPME fiber was carried out for $1 \mathrm{hr}$ for each treatment. Volatile compounds on the fiber were desorbed immediately after sampling the headspace. This procedure was repeated every second day over a period of $12 \mathrm{~d}$ with all groups, i.e., giving a total of six samples per group of three insects and 18 samples for each of the eight treatments. Control samples were obtained by SPME analyses of vials containing a piece of filter paper.

The data from studies of emission of MG compounds by $R$. prolixus adults were analyzed both for individual substances and for pooled samples. This allowed the comparison of emission activity between series (treatments). Every time a MG odor was detected over the samples, this was recorded as a "detection event".

Emission of MG Compounds During Copulation One $R$. prolixus female and one male were gently transferred onto a piece of filter paper inside a $10-\mathrm{ml}$ vial, so as to avoid disturbance and the consequent emission of Brindley's glands' products (Manrique et al. 2006). The vial was closed with a Teflon ${ }^{\circledR} /$ silicone-lined cap. After copulation had begun, volatiles present in the headspace were sampled for $60 \mathrm{~min}$ with a SPME fiber. Volatile compounds were analyzed immediately after sampling the headspace. Twenty assays were performed. Each pair of insects was used only once and then discarded.

Odors Emitted by MGs and Possible Effect on Mating in R. prolixus A pair of bugs was gently introduced into a Petri dish $(10 \times 2 \mathrm{~cm})$ lined with a piece of filter paper and covered with glass to prevent escape. Whether the pair copulated or not was observed for $60 \mathrm{~min}$; if the pair did not commence copulation within this time, it was considered that no copulation occurred. To evaluate the relevance of MG odors for the success of copulation, the proportion of mating pairs under different treatments was compared: (1) pairs in which males had the MG orifices occluded with paraffin $(N=20)$, (2) pairs in which females had the MG orifices occluded with paraffin $(N=20)$, and (3) pairs in which both males and females had the MG orifices occluded with paraffin $(N=20)$. To test whether this treatment affected the behavior of the insects, two series of control assays were performed: (4) a group in which sham males had paraffin applied on a different area of the cuticle without covering the MG orifices $(N=20)$, and (5) a group in which sham females had paraffin applied on a different area of the cuticle without covering the MG orifices $(N=20)$. An additional control series (6) evaluated the mating frequency in intact pairs $(N=20)$. All experiments were performed at $26 \pm 2{ }^{\circ} \mathrm{C}$ and $60 \pm 10 \%$ r.h. The behavior of insects was studied during the first half of the dark phase of their activity cycle.

Chemicals 2-Butanone, 2-pentanone, (2R)-2-butanol, (2S)2-butanol, 2-methyl-3-buten-2-ol, 3-pentanol, 2-pentanol, 4-methyl-2-pentanol, 3-hexanol, and 2-methyl-1-butanol were purchased from Sigma-Aldrich (Brazil). (2S)-3-Methyl2-butanol, (2S)-2-pentanol, and (2S)-4-methyl-2-pentanol were purchased from Lancaster Synthesis (UK). (3E)-2Methyl-3-penten-2-ol was synthesized from methyl crotonate according to Stavinoha et al. (1981), and 4-methyl-3-penten2-ol was synthesized according to Johnson and Rickborn (1970).

(3E)-2-Methyl-3-penten-2-ol Methyl crotonate (0.96 g, $9.6 \mathrm{mmol}$ ) was added dropwise at $<-10^{\circ} \mathrm{C}$ under nitrogen to an ether solution of $1.6 \mathrm{M}$ methyllithium $(20-\mathrm{ml}$, $32 \mathrm{mmol}$ ) over $30 \mathrm{~min}$. The mixture was stirred for an additional $3 \mathrm{hr}$ at $0^{\circ} \mathrm{C}$ before Baeckströms reagent (celite/ $\mathrm{Na}_{2} \mathrm{SO}_{4}, 1: 1 \mathrm{w} / \mathrm{w}$ ) was added. The mixture was filtered and concentrated in vacuo, giving (3E)-2-methyl-3-penten-2-ol as a colorless liquid $(0.57 \mathrm{~g}, 60 \%) .{ }^{1} \mathrm{HNMR}: \delta: 5.63(\mathrm{~m}$, $2 \mathrm{H}), 1.68(\mathrm{~d}, 4.5 \mathrm{~Hz}, 3 \mathrm{H})$, and $1.30(\mathrm{~s}, 6 \mathrm{H}) .{ }^{13} \mathrm{CNMR}: \delta$ : $139.37,122.16,70.89,29.97$, and $17.87 \mathrm{ppm}$.

4-Methyl-3-penten-2-ol Sodium borohydride (0.19 g, $5.0 \mathrm{mmol})$ was dissolved in ethanol $(50 \%, 10-\mathrm{ml})$. 4Methyl-3-penten-2-one (mesityl oxide, $1.0 \mathrm{~g}, 10.0 \mathrm{mmol}$ ) was added dropwise, while stirring at $0^{\circ} \mathrm{C}$. The reaction mixture was stirred at ambient temperature overnight. $\mathrm{K}_{2} \mathrm{CO}_{3}$ was added until the solution was saturated, after which the product was extracted with diethyl ether $(2 \times$ $20-\mathrm{ml})$. The ether phase was washed with brine $(20-\mathrm{ml})$ and dried over $\mathrm{MgSO}_{4}$. Evaporation of the solvent gave 4methyl-3-penten-2-ol as a colorless liquid (0.88 g, 87\%). ${ }^{1} \mathrm{HNMR}: \delta: 5.20(\mathrm{~d}, 8.6 \mathrm{~Hz}, 1 \mathrm{H}), 4.55(\mathrm{dq}, 8.4,6.3 \mathrm{~Hz}$, $1 \mathrm{H}), 1.71(\mathrm{~s}, 3 \mathrm{H}), 1.68(\mathrm{~s}, 3 \mathrm{H})$, and $1.22(\mathrm{~d}, 6.3 \mathrm{~Hz}, 3 \mathrm{H})$. 
${ }^{13}$ CNMR: $\delta: 134.43 ， 129.57,65.03 ， 25.87,23.84$, and $18.23 \mathrm{ppm}$.

A mixture enriched in (2S)-4-methyl-3-penten-2-ol was obtained from the racemate by a lipase-catalyzed reaction (Amano PS immobilized on diatomite, Sigma-Aldrich, Sweden; Brenna et al. 1998). Racemic 4-methyl-3-penten2-ol $(20 \mathrm{mg}, 0.20 \mathrm{mmol})$ and vinyl acetate $(100 \mathrm{mg}$, $0.86 \mathrm{mmol})$ were dissolved in dichloromethane (1-ml). Amano PS-DI $(20 \mathrm{mg})$ was added to the mixture, which was left for $5 \mathrm{hr}$, with occasional shaking. Chiral GC-MS analysis showed a product enriched in the $S$-enantiomer. The assignment of the stereochemistry was based on the well-known stereochemical preference of the Amano-PS lipase (Kazlauskas et al. 1991). A mixture enriched in (3S)hexanol was obtained according to the same protocol.

For all synthesized compounds, ${ }^{1} \mathrm{H}-\mathrm{NMR}$ and ${ }^{13} \mathrm{C}-\mathrm{NMR}$ spectra of $\mathrm{CDCl}_{3}$ solutions were recorded at 500 and $125 \mathrm{MHz}$ by using a Varian Unity spectrometer. Chemical shifts were expressed in ppm in relation to tetramethylsilane. The starting materials were obtained from commercial suppliers and used without further purification. NMR data corresponded well with literature data (Ando et al. 1982; Gau et al. 1999).

Statistical Analyses The results, expressed as the numbers of mating pairs per group of bugs, with or without their glands occluded, were analyzed by means of a Chi-square test followed by multiple comparisons using the Bonferroni correction. Therefore, only comparisons having $P<0.003$ were considered to show a significant difference.

\section{Results}

Identification of Compounds Produced by MGs Our results showed that the MGs of $R$. prolixus are the sources of a complex mixture of volatile substances. Twelve ketones and alcohols were identified in the MGs of $R$. prolixus, with the most abundant compound being 2-methyl-3-buten-2-ol, followed by 2-pentanol, (3E)-2-methyl-3-penten-2-ol, and 4-methyl-3-penten-2-ol (Table 1). The same substances were detected in the MGs of both sexes. The chiral alcohols 2-butanol, 2-pentanol, 4-methyl-2-pentanol, and 3-hexanol were found as $S$-enantiomers only, while 4-methyl-3penten-2-ol (mesityl alcohol) was found as a mixture of the two enantiomers (Table 1). Because 3-methyl-2-butanol and 2-methyl-1-butanol were present at very low concentrations and/or co-eluted with other major compounds on both of the columns used, the chiral analysis was not unequivocal.

Emission of MG Compounds by Virgin Adults MG compounds were consistently detected in the headspace of adult bugs (Fig. 1, Table 2). Detection events (i.e., each time any MG compound was detected) were recorded more frequently in both females and males during the scotophase than the

Table 1 Compounds identified in metasternal glands of $R$. prolixus

\begin{tabular}{|c|c|c|c|c|c|}
\hline Compound & $\mathrm{RT}^{\mathrm{a}}$ & Retention Index ${ }^{b}$ & $\begin{array}{l}\text { Relative Amount } \\
(\%)+\end{array}$ & $\begin{array}{l}\text { Relative Amount } \\
(\%) \hat{d}\end{array}$ & $\begin{array}{l}\text { Relative Amount } \\
(\%)++\delta\end{array}$ \\
\hline 2-Butanone & 2.53 & 909 & $-{ }^{f}$ & $-{ }^{f}$ & $-{ }^{f}$ \\
\hline 2-Pentanone & 3.68 & 979 & $-{ }^{f}$ & $-{ }^{\mathrm{f}}$ & $-{ }^{\mathrm{f}}$ \\
\hline$(2 S)$-Butanol & 4.92 & 1,030 & $5.7 \pm 1.4$ & $2.2 \pm 0.7$ & $4.0 \pm 2.1$ \\
\hline 2-Methyl-3-buten-2-ol & 5.48 & 1,048 & $61 \pm 10$ & $62.2 \pm 7.2$ & $61 \pm 8.6$ \\
\hline 3-Methyl-2-butanol & 7.31 & 1,108 & $1.1 \pm 0.5$ & $0.9 \pm 0.3$ & $1.0 \pm 0.4$ \\
\hline 3-Pentanol & 7.99 & 1,120 & $1.4 \pm 0.4$ & $1.1 \pm 0.2$ & $1.2 \pm 0.4$ \\
\hline$(2 S)$-Pentanol & 8.50 & 1,131 & $20 \pm 4.9$ & $21 \pm 5.3$ & $20 \pm 5.0$ \\
\hline (3E)-2-Methyl-3-penten-2-ol & 10.07 & 1,166 & $6.1 \pm 3.0$ & $5.3 \pm 1.5$ & $5.7 \pm 2.3$ \\
\hline (2S)-4-Methyl-2-pentanol & 10.80 & 1,181 & ${ }_{-}^{\mathrm{f}}$ & ${ }_{-}^{\mathrm{f}}$ & ${ }_{-}^{\mathrm{f}}$ \\
\hline$(3 S)$-Hexanol & 12.00 & 1,207 & ${ }_{-}^{f}$ & $-{ }^{\mathrm{f}}$ & $\mathrm{f}^{\mathrm{f}}$ \\
\hline 2-Methyl-1-butanol & 12.49 & 1,217 & $3.5 \pm 5.1^{\mathrm{g}}$ & $3.3 \pm 4.1^{\mathrm{g}}$ & $3.4 \pm 4.5^{\mathrm{g}}$ \\
\hline$(2 S / 2 R)$-4-Methyl-3-penten-2-ol & 14.99 & 1,267 & $2.1 \pm 1.3$ & $2.5 \pm 0.8$ & $2.3 \pm 1.0$ \\
\hline
\end{tabular}

\footnotetext{
${ }^{a}$ Retention time (SupelcoWax-10 column)

${ }^{\mathrm{b}}$ Retention indices calculated according to Kováts (1965)

${ }^{\mathrm{c}}$ Relative amount (mean and SD) from eight female samples

${ }^{\mathrm{d}}$ Relative amount (mean and SD) from eight male samples

${ }^{\mathrm{e}}$ Relative amount (mean and standard deviation) from all 16 samples

${ }^{\mathrm{f}}$ Average amount $\leq 0.5 \%$ of total amount of compounds in sample

${ }^{\mathrm{g}}$ Three (one $\hat{\delta}$ and two ) out of 16 samples contained $10.5-13.1 \%$, and the remaining 13 samples $0.0-3.4 \%$
} 


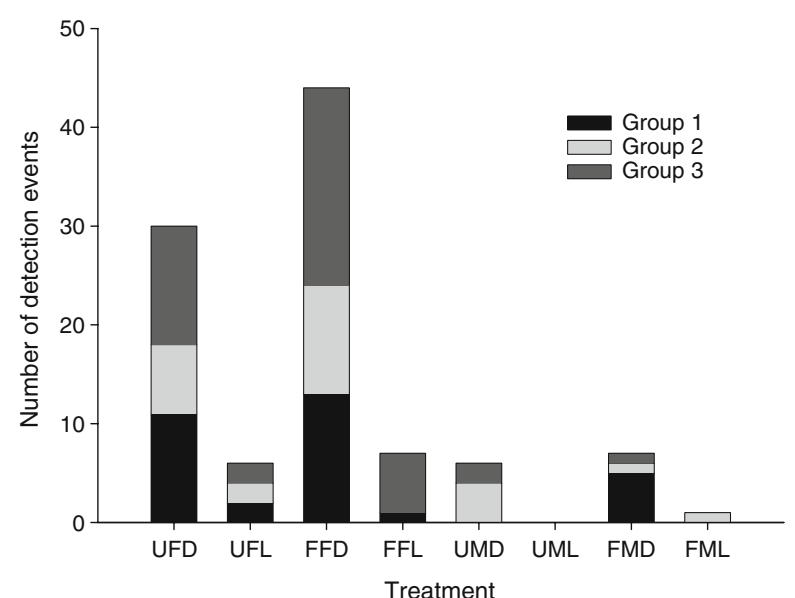

Fig. 1 Number of detection events of various R. prolixus metasternal gland compounds in different groups (each of three individuals) of fed/unfed males and females during the light and dark phases. UFD Unfed females during dark phase, UFL unfed females during light phase, $F F D$ fed females during dark phase, $F F L$ fed females during light phase, $U M D$ unfed males during dark phase, $U M L$ unfed males during light phase, FMD fed males during dark phase, $F M L$ fed males during light phase

photophase (Fig. 1, Table 2). In general, more detection events were recorded from females than males under all experimental conditions (Fig. 1, Table 2). There was no apparent difference between unfed and fed insects.

Nine out of the 12 compounds found in the MGs were detected in the headspace over females over all the different treatments (Table 2), whereas only three of them were found in the headspace over males (Table 2). 2-Methyl-3- buten-2-ol was the most frequently detected compound in these analyses (Table 2).

Emission of MG Compounds During Copulation In 19 out of 20 assays with pairs, a successful copulation resulted. The average duration of copulation was $49.7 \pm 3.6 \mathrm{~min}$. At least one of the compounds identified in the MGs was detected during $70 \%$ of the copulations. The most abundant compound produced by the MGs (2-methyl-3-buten-2-ol) was detected in $40 \%$ of the copulations. The compound most frequently found during copulation (in $60 \%$ of the samples) was 2-methyl-1-butanol. 2-Pentanone was detected in $10 \%$ of the assays.

Relevance of the Odors Emitted by MGs for the Success of Mating The percentage of copulation of untreated control pairs was $95 \%$ (Fig. 2, N=20). This was not significantly different from the percentages of copulation observed in sham-operated male and female treatments (Fig. 2). However, occlusion of female MG orifices or male MG orifices resulted in significant $(P<0.003)$ decreases in copulation frequencies $(30 \%, N=20$ and $15 \%, N=20$, respectively). Occlusion of both male and female orifices also resulted in a significant $(P<0.003)$ decrease (relative to the controls) of mating percentage $(15 \%, N=20)$.

\section{Discussion}

The results show that the metasternal glands of $R$. prolixus are a rich source of volatile compounds. GC-MS analysis

Table 2 The detection of Rhodnius prolixus metasternal gland compounds in various treatments, related to sex, feeding status, and time of day

\begin{tabular}{|c|c|c|c|c|c|c|c|c|}
\hline Compound & UFD & UFL & FFD & FFL & UMD & UML & FMD & FML \\
\hline 2-Butanone & 1 & 0 & 3 & 0 & 0 & 0 & 0 & 0 \\
\hline 2-Pentanone & 2 & 0 & 2 & 0 & 0 & 0 & 0 & 0 \\
\hline$(2 S)$-Butanol & 3 & 1 & 8 & 1 & 0 & 0 & 0 & 0 \\
\hline 2-Methyl-3-buten-2-ol & 7 & 2 & 11 & 3 & 4 & 0 & 6 & 1 \\
\hline 3-Methyl-2-butanol & 5 & 0 & 4 & 0 & 0 & 0 & 0 & 0 \\
\hline 3-Pentanol & 0 & 0 & 0 & 0 & 0 & 0 & 0 & 0 \\
\hline$(2 S)$-Pentanol & 4 & 1 & 5 & 1 & 1 & 0 & 0 & 0 \\
\hline (3E)-2-Methyl-3-penten-2-ol & 0 & 1 & 0 & 1 & 0 & 0 & 0 & 0 \\
\hline (2S)-4-Methyl-2-pentanol & 0 & 0 & 0 & 0 & 0 & 0 & 0 & 0 \\
\hline$(3 S)$-Hexanol & 0 & 0 & 0 & 0 & 0 & 0 & 0 & 0 \\
\hline 2-Methyl-1-butanol & 7 & 1 & 11 & 1 & 1 & 0 & 1 & 0 \\
\hline$(2 S / R)-4-M e t h y l-3-p e n t e n-2-o l$ & 0 & 1 & 0 & 1 & 0 & 0 & 0 & 0 \\
\hline Total & 29 & 7 & 44 & 8 & 6 & 0 & 7 & 1 \\
\hline
\end{tabular}

Numbers indicate the detection frequency for each compound (18 SPME samples per treatment).

$U F D$ Unfed female sampled during dark phase, UFL unfed female sampled during light phase, $F F D$ fed female sampled during dark phase, $F F L$ fed female sampled during light phase, $U M D$ unfed male sampled during dark phase, $U M L$ unfed male sampled during light phase, $F M D$ fed male sampled during dark phase, FML fed male sampled during light phase 


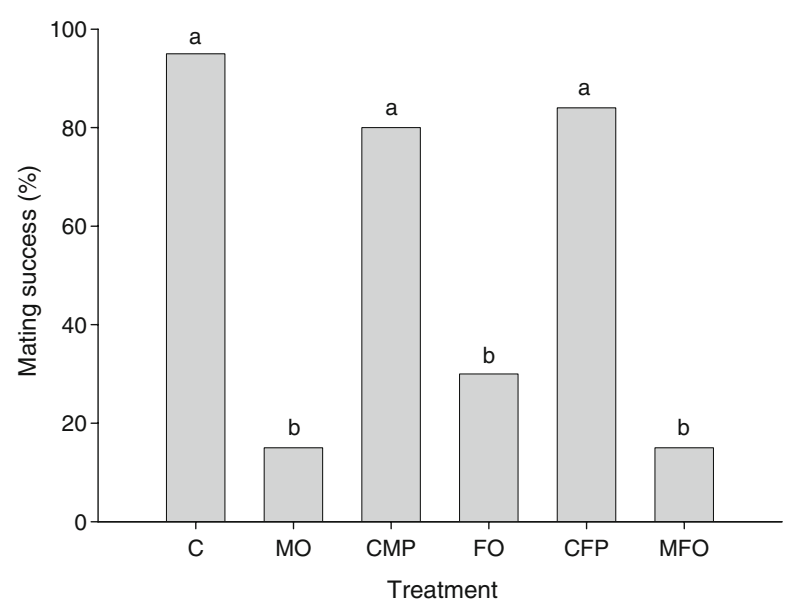

Fig. 2 Copulation (\%) of $R$. prolixus pairs: $C$ Control (intact) pairs, $M O$ males with occluded MG orifices, $C M P$ control males treated with paraffin on a different part of their body surface, $F O$ females with occluded MG orifices, CFP control females treated with paraffin on a different part of their body surface, $M F O$ males and females with occluded MG orifices. Different letters atop treatments represent significant differences (chi-square test followed by Bonferroni multiple comparisons, $P<0.003$ )

revealed a mixture of 12 volatile ketones and alcohols, with the most abundant compounds being 2-methyl-3-buten-2ol, (2S)-pentanol, (3E)-2-methyl-3-penten-2-ol, and the enantiomers of 4-methyl-3-penten-2-ol. None of these compounds had previously been reported in a triatomine species. However, 2-methyl-3-buten-2-ol has been reported as part of the aggregation pheromones of several species of bark beetles (Giesen et al. 1984; Klimetzek et al. 1989; Schlyter et al. 1992) and also as part of the alarm pheromone of the hornet wasp, Vespa crabro (Veith et al. 1984). 2-Pentanol has been found in the alarm pheromone of hornet wasps (Ono et al. 2003; Ono 2005), as an attractant to fruits for the coleopterans, Carpophilus hemipterus and Conotrachelus nenuphar (Phelan and Lin 1991; Prokopy et al. 2001), and as part of the defensive secretions of Polyzosteria and related cockroaches (Wallbank and Waterhouse 1970). To our knowledge, 2-methyl-3-penten2-ol and 4-methyl-3-penten-2-ol have not been reported as semiochemicals for any insect species. Minor components of the secretions, 2-butanone, 2-methyl-1-butanol, and 3hexanol have been found previously in MG secretions of $T$. infestans by Manrique et al. (2006).

Interestingly, the saturated alcohols we identified in $R$. prolixus all had an $(S)$-configuration, suggesting a common enzymatic system in their biosynthesis. In accord with what is known about the biosynthesis of 2-methyl-3-buten-2-ol in bark beetles (Lanne et al. 1989; Martin et al. 2003; Seybold et al. 2006), it is conceivable that a common allylic carbocation in the biosynthetic pathway gives rise to both (3E)-2-methyl-3-penten-2-ol and 4-methyl-3-penten-2-ol. Hydration at the allylic positions of the carbocation would form 2-methyl-3-penten-2-ol and 4-methyl-3-penten-2-ol. The latter addition appears not to be stereoselective as both enantiomers of 4-methyl-3-penten-2-ol are formed.

We demonstrated that the volatile compounds found in the MGs of $R$. prolixus are emitted by virgin adult bugs of both sexes. Emission of these compounds was detected more frequently from females than males. Females also released these chemicals more frequently during the early hours of the scotophase, the period when sexual activity in this species is at its peak (Manrique, personal communication). That these compounds may be involved in sexual communication is suggested by their detection, albeit in low amounts (e.g., 10-100 pg for 2-pentanol) over copulating pairs of $R$. prolixus. That only three of the MG compounds were detected over copulating pairs could have been due to the very low concentration of compounds emitted by bugs. It is worth noting that the SPME collections for analysis of MG content were of headspace above 12 glands heated to $50^{\circ} \mathrm{C}$, whereas, at most, the headspace above a pair of bugs emitting volatiles consisted of the contents of four glands at $26^{\circ} \mathrm{C}$. For most of the compounds identified in the glands (i.e., from two MGs), the amount was close to the detection limit of our instrument. Manrique et al. (2006) detected 3-pentanone, the main component of the MG secretions of T. infestans, over copulating pairs, and suggested that this species may use MG odors for communication during mating. A role for the MG odors in the sexual behavior of $R$. prolixus was further suggested by our occlusion experiments in which occlusion of the MG orifices of either males or females resulted in a significant decrease in copulation, relative to the various controls. A similar result was obtained for $T$. infestans (Crespo and Manrique 2007).

It is worth noting that we did not detect any Brindley's gland secretions during our sampling of copulating pairs. These secretions have previously been detected (Ríos Candelaria 1999; Guerenstein and Guerin 2004) over $R$. prolixus mating pairs, and it has been suggested that they may be involved in sexual communication. However, it cannot be excluded that the detection of Brindley's gland compounds in those studies may have been the result of an alarm response (Manrique et al. 2006) rather than a sexual signal. Further work is needed to clarify the role of Brindley's glands secretions in the sexual behavior of $R$. prolixus.

Overall, our data show that the release of compounds found in the MGs of adult $R$. prolixus corresponds with sexual activity of this species, and that furthermore, females 
appear to release greater quantities of these compounds than males. However, whether these chemicals actually mediate sexual behavior in this species is unknown. Further work is required to determine whether the compounds are directly involved in mediating sexual behavior of adults and, if so, what is their precise role. If these chemicals are attractive to adult $R$. prolixus, they could prove useful as chemical baits in traps for monitoring or controlling $R$. prolixus populations, thereby limiting the transmission of Chagas disease to humans. The development of new methods for controlling $R$. prolixus is critical as certain populations have already developed resistance to the pyrethroid insecticides used in control programs (Zerba 1999).

Acknowledgements We thank Dr. C. Lazzari and Dr. G. Manrique for reviewing the manuscript and the reviewers for their valuable comments. We also thank Dr. C. Zani for kindly allowing access to the GC-MS set-up. This work was supported by Instituto René Rachou/ FIOCRUZ, CAPES, FAPEMIG (Brazil), by the Swedish International Development Cooperation Agency (SIDA) and by the University of Kalmar (Sweden)

\section{References}

Ando, W., Sato, R., Yamashita, M., AKasaKa, T., and MiYazaKi, H. 1982. Quenching of singlet oxygen by 1,3,5-triaryl-2-pyrazolines. J. Org. Chem. 48:542-546.

BAldwin, W. F., KNight, A. G., and LynN, K. R. 1971. A sex pheromone in the insect Rhodnius prolixus (Hemiptera: Reduviidae). Can. Entomol. 103:18-22.

Birkett, M. A., Bruce, T. J. A., Martin, J. L., Smart, L. E., OAKLEY, J., and WADHAMS, L. J. 2004. Responses of female orange wheat blossom midge, Sitodiplosis mosellana, to wheat panicle volatiles. J. Chem. Ecol. 30:1319-1328.

BRINDLEY, M. D. H. 1930. On the metasternal scents-glands of certain Heteroptera. Trans. Ent. Soc. Lond. 78:199-208.

Brenna, E., Fronza, G., Fuganti, C., Ighetti, A., and Serra, S. 1998. Enzyme-mediated preparation of the single enantiomers of the olfactory active components of the woody odorant timberol. Helv. Chim. Acta. 82:1762-1773.

Crespo, J., and Manrique, G. 2007. Mating behavior of the hematophagous bug Triatoma infestans: Role of Brindley's and metasternal glands DOI 10.1016/j.jinsphys.2007.03.014.

Cruz-López, L., Morgan, E. D., and Ondarza, R. N. 1995. Brindley's gland exocrine products of Triatoma infestans. Med. Vet. Entomol. 9:403-406

Cruz-López, L., Malo, E. A., ojas, J. C., and Morgan, E. D. 2001. Chemical ecology of triatomine bugs: vectors of Chagas disease. Med. Vet. Entomol. 15:351-357.

GaU, A. H., Lin, G. L., UANG, B. J., LiaO, F. L., and Wang, S. L. 1999. Regio- and diastereoselective ene reaction of 4-phenyl1,2,4-triazoline-3,5-dione with chiral allylic alcohols and their derivatives. J. Org. Chem. 64:2194-2201.

Giesen, H., Ohnle, U., Vite, J. P., Pan, M. L., and Francke, W. 1984. The aggregation pheromone of the Mediterranean pine bark-beetle Ips (Orthotomicus) erosus. Z. Angew. Entomol. 98:95-97.
Guerenstein, P. G., and Guerin, P. M. 2004. A comparison of volatiles emitted by adults of three triatomine species. Entomol. Exp. Appl. 111:151-155.

JOHNSON, M. R., and RicKBORN, B. 1970. Sodium borohydride reduction of conjugated aldehydes and ketones. J. Org. Chem. 35:1041-1045.

Kazlauskas, R. J., Weissfloch, A. N. E., APPaport, A. T., and CUCCIA, L. A. 1991. A rule to predict which enantiomer of a secondary alcohol reacts faster in reactions catalyzed by cholesterol esterase, lipase from Pseudomonas cepacia, and lipase from Candida rugosa. J. Org. Chem. 56:2656-2665.

KlimetZeK, D., BARTEls, J., and Francke, W. 1989. The pheromone system of the elm bark beetle Pteleobius vittatus (F.) (Col., Scolytidae). J. Appl. Entomol. 107:518-523.

KovÁTS, E. 1965. Gas chromatographic characterization of organic substances in the retention index system, pp. 229-247, in J. C. Giddings, and R. A. Keller (eds.). Advances in Chromatography, Vol1. Edward Arnold Ltd., London.

Lanne, B. S., Ivarsson, P., Johnsson, P., Bergström, G., and WASSGREN, A. B. 1989. Biosynthesis of 2-methyl-3-buten-2-ol, a pheromone component of Ips typographus (Coleoptera: Scolytidae). Insect Biochem. 19:163-167.

Manrique, G., and Lazzari, C. R. 1995. Existence of sex pheromone in Triatoma infestans (Hemiptera: Reduviidae): IBehavioural Evidence. Mem. Inst. Oswaldo Cruz. 90:645-648.

Manrique, G., Vitta, A. C., Ferreira, R. A., Zani, C. L., Unelius, C. R., LAZZARi, C. R., Diotaiuti, L., and Lorenzo, M. G. 2006. Chemical communication in Chagas disease vectors. Source, identity, and potential function of volatiles released by the metasternal and Brindley's glands of Triatoma infestans adults. J. Chem. Ecol. 32:2035-2052.

Martin, D., Bohlmann, J., Gershenzon, J., Francke, W., and Seybold, S. J. 2003. A novel sex-specific and inducible monoterpene synthase activity associated with a pine bark beetle, the pine engraver, Ips pini. Naturwissenschaften 90:173-179.

Monteiro, F. A., Barrett, T. V., FitzPatrick, S., Cordon-osales, C., Feliciangeli, D., and Beard, C. B. 2003. Molecular phylogeography of the Amazonian Chagas disease vectors Rhodnius prolixus and R. robustus. Mol. Ecol 12:997-1006.

OnO, M., Terabe, H., Hori, H., and SASAKI, M. 2003. Components of giant hornet alarm pheromone. Nature 424:637-638.

ONO, M. 2005. Semiochemicals that regulate social behaviour of hornets. Aroma Res. 6:230-236.

Phelan, P. L., and Lin, H. 1991. Chemical characterization of fruit and fungal volatiles attractive to dried-fruit beetle, Carpophilus hemipterus (L.) (Coleoptera: Nitidulidae). J. Chem. Ecol. 17:1253-1272.

Prokopy, R. J., Phelan, P. L., Wright, S. E., Minalga, A. J., BARGER, R., and LESKEY, T. C. 2001. Compounds from host fruit odor attractive to adult plum curculios (Coleoptera: Curculionidae). J. Entomol. Sci. 36:122-134.

Rojas, J. C., Ríos-CANDElaRia, E., CRUZ LÓPEZ, L., SANTIESTEBAN, A., Bond-CompeAn, J. G., BRINDIS, Y., and MALO, E. A. 2002. A reinvestigation of Brindley's gland exocrine compound of Rhodnius prolixus (Hemiptera: Reduviidae). J. Med. Entomol. 39:256-265.

Ríos-CANDELARIA, E. 1999. Análisis químico y conductual de los compuestos volátiles emitidos por Rhodnius prolixus (Hemiptera: Reduviidae), vector de la enfermedad de Chagas. $\mathrm{PhD}$ dissertation. Universidad Autónoma de Chiapas, México.

SChlyter, F., Birgersson, G., BYERS, J. A., and BAKKe, A. 1992. The aggregation pheromone of Ips duplicatus and its role in competitive interactions with I. typographus. Chemoecology $3: 103-112$. 
SCHOFIELD, C. J. 1994. Triatominae, biología y control. Eurocommunica Publications, United Kingdom.

Seybold, S. J., Huber, D. P. W., Lee, J. C., Graves, A. D., and BoHlmanN, J. 2006. Pine monoterpenes and pine bark beetles: a marriage of convenience for defense and chemical communication. Phytochem. Rev. 5:143-178.

Stavinoha, J. L., Mariano, P. S., Leone-Bay, A., Swanson, R., and BRACKEN, C. 1981. Photocyclizations of $N$-allyliminium salts leading to the production of substituted pyrrolidines. J. Am. Chem. Soc. 103:3148-3160.

Veith, H. J., Koeniger, N., and Maschwitz, U. 1984. 2-Methyl-3butene-2-ol, a major component of the alarm pheromone of the hornet Vespa crabro. Naturwissenschaften 71:328-329.
Wallbank, B. E., and Waterhouse, D. F. 1970. The defense secretions of Polyzosteria and related cockroaches. J. Insect Physiol. 16:2081-2096.

WARD, J. P. 1981. A comparison of the behavioural responses of the haematophagous bug, Triatoma infestans to synthetic homologues of two naturally occurring chemicals ( $n$ - and isobutyric acid). Physiol. Entomol. 6:325-329.

World Health ORganization. 2005. Report of the Scientific Working Group on Chagas Disease. http://www.who.int/tdr/ diseases/chagas/default.htm.

ZerbA, E. N. 1999. Susceptibility and resistance to insecticides of Chagas disease vectors. Medicina-Buenos Aires 59:4146. 